\title{
El campo social de la migración rumana
}

\author{
Vincent Maisongrande \\ Doctorand en Antropologia Social i Cultural \\ maisongrande.vincent@yahoo.fr
}

Resumen: Partiendo de los datos etnográficos de un trabajo de tesis sobre las migraciones rumanas en Europa desde la década de 1990, el artículo explica las grandes etapas históricas del fenómeno e introduce la noción de "campo social de la migración", ampliamente inspirada en los trabajos de Bourdieu. En una segunda parte de aplicación al tema de estudio, discutimos, mediante ejemplos, algunos de los caracteres especificos de este objeto conceptual. En este sentido, se considera muy útil para entender mejor las lógicas socioculturales de los procesos migratorios.

Palabras clave: campo social, migraciones rumanas, redes migratorias, habitus, campo migratorio.

Abstract: Based on an ethnographic data drawn from a thesis on the Romanian migration in Europe since the 90s, the article presents the historical stages of the phenomenon and introduces the notion of "social field of migration" which is largely inspired by the work of Bourdieu. In a second part, applying it to the object of study, we use define by example some specific characters of this conceptual object. This one appears to be very useful in order to understand better the sociocultural logics of migration processes.

Keywords: social field, Rumanian's migration, migration networks, habitus, migration field. 


\section{Oportunidades, objeto y planteamientos}

Las reflexiones presentadas aquí, los elementos etnográficos y su contextualización, las formulaciones teóricas y las reflexiones analíticas, constituyen un avance de la tesis doctoral que estoy preparando. Su punto de partida es la observación y el seguimiento a lo largo del tiempo de fuertes y sostenidas pautas de movilidad migratoria desarrolladas por grupos de origen rumano hacia $y$ dentro de distintos países europeos.

Antes de empezar, debo aclarar dos puntos acerca de la postura de investigación. En primer lugar, mi relación con estos grupos y mis conocimientos de sus prácticas estaban ya muy desarrollados antes de tratar de objetivizarlas para estudiarlas: nos conocimos jóvenes, hace muchos años. En segundo lugar, cabe decir que mi interés por el tema, mis planteamientos y orientaciones para abordarlo, pero también mis posibilidades metodológicas para llevar a cabo este trabajo, están ampliamente condicionados por esta larga relación previa. Y en la medida en que dicha relación continuará y que sus evoluciones influirán también de manera importante en nuestras respectivas biografías posteriores (para algunas de las personas con las que trabajo más que para otras), es evidente que aquella relación - como mi papel activo en ella y todas mis acciones o caracteres que hayan podido influir - tendrá que pasar, para la tesis, por el mismo filtro del socioanálisis que se aplicará al resto de sus vivencias, tanto en migración como fuera. Dicho esto, aquí no detallaré demasiado estos puntos ya que aprovecharé el artículo para presentar otros elementos de la investigación en curso.

Así, me limitaré a decir que hago mi entrada en escena en el verano del 2004 cuando, sin que tenga todavía ningún tipo de interés "antropológico" en ello ${ }^{1}$, conocí en Limoges, Francia, a algunos migrantes rumanos que estaban "de paso" por la ciudad. Pasando sobre lo "extrañas" y "miserables" que podían parecer sus condiciones de vida, desconocidas (literalmente) en aquel entonces en el paisaje autóctono — se dedicaban a la mendicidad y vivían en sus coches-, digamos que quedé enseguida desconcertado por su inhabitual relación con el

1 Otros sí. Resumiendo, solo cabe decir que, por muy "fruto de la casualidad" que nos pudo parecer a todos el encuentro en su momento, no lo era del todo, y es evidente que había algún que otro resorte estructural obrando en segundo plano, eso sí, de manera esencialmente inconsciente para los —incluido yo- que "realizaban" dicho resorte. Lo mismo se puede decir del mantenimiento posterior de la relación. Así, la teoría que intento emplear, de interrelación dinámica entre, por una parte, contingencias históricas y elecciones personales estratégicas y, por otra, desencadenantes estructurales, se aplica por supuesto a mi propio caso. 
lugar y sus prácticas en él, y también por el aparente carácter internacional de sus espacios socioculturales de referencia. Bien porque se encontraban visiblemente en lo más bajo de lo que yo, lugareño, reconocía "naturalmente" como la escala social local ${ }^{2}$, bien porque mostraban comportamientos y desarrollaban estrategias yendo a veces claramente en contra del "más básico sentido común" (local), lo verdaderamente intrigante - e involuntariamente chocante, lo que me gustaba - es que parecían desenvolverse bastante bien, hasta por momentos disfrutar - como si se tratase de vacaciones - de su estancia por la zona y de su descubrimiento (estratégico) de la ciudad y sus alrededores (mi ciudad y mi región, que me tenían personalmente muy asqueado en aquel entonces, pero que redescubrí de manera distinta con ellos). Y a todas luces sacaban un buen provecho de todo aquello, económico y lúdico a partes iguales. Se desplazaban también frecuentemente por toda la ciudad y su periferia, a veces más lejos, y además estaban en contacto - continuamente intercambiaban noticias, informaciones, consejos y ayudas, ocasionalmente se visitaban - con muchos otros pequeños grupos de migrantes como ellos, temporales o más asentados, repartidos por todo el centro-oeste de Francia, Italia, España y, cómo no, Rumanía. Todo aquello me resultaba muy peculiar y atractivo a la vez, muy "moderno" y "globalizado", aunque también miserable. Resulta que rápidamente nos hicimos amigos.

Después de este primer verano el grupo primigenio, constituido por jóvenes que solo eran amigos y conocidos (es importante señalarlo), se separó. Todos regresaron a Rumanía al vencerles el visado — de tres meses de duración-, mientras que yo también me iba a estudiar a otra zona al sur de Francia. A los pocos meses volvieron a pasar por Limoges, pero ya no viajaban juntos ya que entre tanto el grupo original se había dividido en dos (reconfigurado), cada una de sus partes acompañada por otras personas, amigos y familiares. Mantuvimos el contacto más con un grupo que con el otro, en parte desde la distancia, en parte porque nos veíamos con cierta regularidad: cuando volvía a ver a mis padres y amigos en mi ciudad, cuando venían a visitarme a Montpellier o cuando en alguna ocasión nos encontrábamos en España, donde tenían primos afincados e iban a trabajar durante las temporadas de cosecha. Y a medida que

2 Por los marcadores simbólicos que ostentaban, su ropa humilde y pasada de moda, su actividad muy estigmatizada y su desconocimiento casi completo del idioma o de las lógicas institucionales vigentes en Francia, entre otros elementos que son usados por los agentes sociales para posicionarse e identificar a los demás en sociedad. 
la relación se estrechaba, que nos involucrábamos mutuamente en un juego de atenciones, ayudas y reconocimientos recíprocos, yo pasaba cada vez más a constituir para ellos una suerte de "apoyo logístico en migración" - papel similar y complementario al que jugaban también otros contactos suyos, tanto migrantes como autóctonos, repartidos por todas las zonas por las que circulaban $^{3}$ - Q Que se entienda que aquí todo era "buena voluntad sincera” y aprecio mutuo - por lo menos con el grupo con el cual, y justamente por eso, mantuvimos contacto-. De buen grado y sin que necesitaran pedírmelo (incluso teniendo a menudo que insistir), les habré prestado ayuda para alguna llamada u otras gestiones que tuvieran que hacer en francés o habré utilizado algún contacto mío para sacarles de alguna situación delicada..., pequeñas muestras de respeto a las cuales se empeñaban a toda costa a responder como podían (insistiendo a su vez) mediante pequeños regalos — no siempre acertados para mi gusto, si bien me bastaba con la intención-, invitándome continuamente a compartir sus comidas, sirviéndose ellos mismos de algún contacto suyo para arreglarme gratis el coche, etc. A raíz de ello, la articulación de roles típica de este tipo de relaciones y sus afectos correspondientes no tardaron en cobrar forma ${ }^{4}$.

La relación se mantuvo con el paso de los años, llegando a estrecharse progresivamente para, de muchas maneras, cobrar gran importancia en nuestras trayectorias respectivas, migratorias o no. Mi posterior traslado a España - temporal primero y luego definitivo, en Tarragona - tendrá, por ejemplo, mucho que ver con la simultánea y progresiva reorientación hacia aquí de sus movilidades migratorias (como dicha reorientación tendrá, a su vez, ciertamente algo que ver con mi presencia, las dos cosas estando integradas y siendo acumulativas).

No seguiré aquí con esta historia ya que solo se trata de indicar que llevo casi 10 años siguiendo y formando parte del grupo que sirve de base al estudio, que en el fondo hemos crecido y nos hemos formado juntos en la migra-

3 Se descubrirá luego, comparando su caso con otros, que esta "red social (externa) de apoyo en migración" acababa constituyendo un importante factor de configuración de sus migraciones y de elección (no del todo libre entonces, al estar condicionada por la presencia o no de contactos valiosos) de sus espacios de destino y de paso de sus movilidades (Maisongrande, 2008).

4 Insisto, debido a las acciones voluntarias de las personas involucradas, no exentas de condicionantes e intereses específicos estructurales, mayormente inconscientes; un "interés mutuo bien comprendido", como diría Bourdieu, el cual siempre acompaña y es necesario al desempeño y la integración de los roles sociales y de sus afectos correspondientes. 
ción. Es a través de sus experiencias, buena parte de las cuales he podido vivir en primera persona, que descubrí poco a poco y "desde abajo" cuáles eran las lógicas contemporáneas de las migraciones internacionales en Europa ${ }^{5}$, y que pude ampliar horizontes $y$, más importante seguramente, cambiar perspectivas. Involucrándome también en movilidades parecidas y deseando conseguir una mayor comprensión tanto de sus vivencias como de las mías es como creció mi interés científico acerca de estas cuestiones.

Aparte de la ventaja de disponer de gran cantidad de información muy específica y de primera mano para la realización de esta clase de estudios, este compromiso personal muy anterior me permite sobre todo trabajar sobre estos fenómenos hasta el nivel más microsocial, con y sobre personas concretas y conocidas, sobre sus caracteres, sus relaciones, sus representaciones, sus vivencias..., y tratar de entender cómo ellos mismos las pueden experimentar; también sobre sus trayectorias de vida y migratorias a largo plazo y no solo (aunque también) a posteriori usando entrevistas biográficas (que tienen las limitaciones que sabemos), sino más bien como una suerte de etnografía continua de "baja intensidad" (combinada, claro está, con varios otros períodos de etnografía de campo muy intensiva y de recogida sistemática de datos, entre 2008 y 2012).

\footnotetext{
5 A pesar de la aparentemente gran - y muy comentada - diversificación de los flujos migratorios y sus modalidades hacia Europa occidental durante la década de 1990 y parte de la de 2000, se observa desde entonces como las lógicas estratégicas de movilidad, las actividades desempeñadas por los migrantes y la organización de estas, los imaginarios, las figuras y los roles que se usan y se reconocen en migración..., van pareciéndose cada vez más, o como mínimo van integrándose, entre todos estos flujos migratorios europeos en principio muy diversos. Todo esto, desde luego, no viene solo condicionado por las acciones de los propios migrantes - a veces sí, como lo demuestran muy bien los trabajos de Tarrius-, sino más bien porque dichas acciones tienen que configurarse en relación con unos contextos específicos de destino, físicos, históricos, jurídicos y socioculturales, los cuales, si no son uniformes, están ellos también cada vez más integrados a nivel europeo. Así, distintos fenómenos como la precarización creciente del estatus jurídico-administrativo de los inmigrantes; la feminización de los flujos y la diversificación de los demás caracteres del "perfil social de origen" de los migrantes; la diversificación de sus actividades y de los espacios de origen, de destino y de paso que articulan en su desempeño; el incremento de sus movilidades locales e internacionales y de la combinación de las dos; el creciente uso estratégico de redes de contactos informales de carácter comunitario/ familiar con la aparición en estas de figuras estructurales típicas (pioneros, intermediarios/gestores, notables, seguidores...) que van periódicamente cambiando de portadores; o también la sucesión muy rápida de fenómenos de adaptación/cambio de actividad y de reorientación/reubicación de los flujos y de los “territorios de movilidad" - estas reorientaciones pudiendo, además, ser realmente masivas, como hacia el Mediterráneo entre el principio y la mitad de la década de 2000...- (Simon, 1995; Tarrius, 1996; Hily, Doraï y Ma Mung, 1998; Wihtol de Wenden, 2001). Y todo aquello que se hace ahora visible — lo que no significa que no existiera antes - parece estar cada vez más generalizado, y ser más o menos similar, en muchos colectivos migrantes (tanto "nuevos" como "antiguos") a lo largo y ancho del continente.
} 
Y aparte de una descripción detallada de este fenómeno migratorio concreto, lo que aquí me gustaría analizar son los procesos — sociales, culturales, históricos - que condicionan su configuración y reconfiguración continua. El planteamiento y el objetivo serían buscar entender cómo son, en el fondo, las producciones personales y específicas de los propios migrantes (influenciadas por multitud de factores) que configuran a nivel más general las prácticas en migración y la forma de los flujos - cómo estas migraciones participan a su vez en los procesos de reproducción y/o cambio social en los espacios socioculturales de origen, de destino y de paso de los flujos que ponen en contacto y articulan-, y ver cómo todo esto se retroalimenta continuamente en un baile sin fin. Es decir, partiendo del ejemplo y del análisis de este objeto concreto - las migraciones rumanas consideradas como un campo social específico-, intentaríamos situarnos en esta articulación compleja y dinámica entre general y particular, entre estructura y actos individuales, que las ciencias sociales tratan de aclarar desde sus orígenes.

Llevar a cabo tal proyecto requiere poder monitorizar prácticamente del todo, y lo más a fondo posible, el proceso sociocultural que se toma como objeto de estudio y también el papel de sus actores. Y es más que nada esta relación previa y duradera con estos grupos migrantes lo que me permite emprender tal trabajo.

\section{El grupo y sus migraciones}

Estos migrantes son originarios del suroeste de Rumanía, de una región fronteriza con Serbia. Son en parte urbanos/neourbanos, en parte rurales, y provienen de distintos pueblos más o menos cercanos a la capital de región, Drobeta-Turnu Severin. Sus grupos migratorios ${ }^{6}$ integrados son mixtos, gitanos

6 Constituidos por las personas, tanto migrantes como no migrantes, con las cuales más a menudo interactúan tanto en la migración como en interacciones sociales relacionadas, aunque sea de forma indirecta, con la migración. Y para contestar aquí a la clásica controversia acerca de saber quién entra y quién no en el "campo social transnacional", diría que, si consideramos que la esencia de este se basa - como la de cualquier otro campo social- en unos imaginarios propios que lo definen como tal e influyen sobre las representaciones (y a continuación las acciones) de los que están en contacto con él, hasta donde estos imaginarios puedan influir en las interacciones sociales entre agentes, aunque sea de manera muy tenue y muy indirecta, no tiene —como tampoco los tiene ningún otro campo social— límites establecidos más que los que le queramos dar a efectos de su objetivación. El propio término de campo (como un "campo magnético") nos lo indica: no da una idea de límites claros, marcados, sino más bien una idea de difuminación y atenuación progresiva de sus efectos a medida que se aleja del centro. $\mathrm{Si}$, pasado un punto arbitrario, dichos efectos se vuelven tan tenues que ya no se pueden medir o considerar relevantes a efectos de estudio, no es por ello que dejen que existir. 
y no gitanos sobre todo, pero también de otras "etnias" o nacionalidades. En contacto desde la época del comunismo por relaciones familiares, de amistad o de vecindad, participaron colectivamente en prácticamente todas las oleadas migratorias que conoció el país, convirtiéndose poco a poco en especialistas. Resumiré rápidamente su historial:

1. Justo a principios de la década de 1990 (y con la caída del régimen de Ceausescu), la zona conoce pérdidas masivas de empleo a causa de las primeras reestructuraciones industriales y la descolectivización agrícola. En época comunista, ante las recurrentes penurias e incoherencias de la planificación económica, ya era muy habitual en Rumanía recurrir al mercado negro. Encontrándose entonces sin recursos, muchas familias se vuelcan más decididamente en este, donde combinan y articulan sucesivamente (o a la vez) todo tipo de prácticas informales: cambio ilegal de divisas, autoconsumo agrícola y venta directa en negro de los excedentes, tráfico fronterizo de tabaco y gasolina, trabajos temporales sin declarar, trueque... Imitándose unos a otros, muchos son también los que empiezan a comerciar con las aldeas serbias del otro lado del Danubio (entonces más ricas y donde se había emigrado desde la década de 1970 hacia Austria y Alemania) y/o consiguen también allí trabajos diversos y temporales en la construcción o la agricultura ${ }^{7}$.

2. Entre 1991 y 1993, en plena época de reconfiguración política generalizada en toda Europa del Este, importantes grupos de gitanos de la zona marchan a Alemania oriental. En ello imitan a otras minorías religiosas o étnicas del país $^{8}$ que aprovechan allí la, entonces muy favorable, política estatal de "reinte-

\footnotetext{
7 Existía por toda la zona una vieja tradición de comercio ocasional y no profesional —unas prácticas también muy frecuentes en otros países del bloque del Este desde la década de 1960 - que consistía en comprar una pequeña cantidad de cualquier producto que tuviera alguna diferencia de precio más o menos notable entre los dos países para ir y volver en un mismo día al mercado de la ciudad del otro lado de la frontera, venderlo rápidamente y volver a casa con las ganancias (Morokvasic, 1999; Sandu, Radu, Constantinescu et alii, 2004; Radu y Radu, 2006).

8 Como muchos otros países balcánicos o semibalcánicos, Rumanía, mayormente poblada por personas de lengua y afiliación rumana y de religión ortodoxa, contaba también con numerosas minorías de toda índole: alemanes, gitanos, judíos, moldavos, húngaros y turcos. Asimismo, existían diversas iglesias protestantes y una segmentación bastante marcada y relevante a nivel social, económico y político. Esto se remonta a la época de la dominación otomana, ya que el Imperio tendía a asentar su dominación sobre la zona y sus pueblos mediante la instrumentalización y el refuerzo de este principio clasificador ( $y$ en esto notamos que no hacía otra cosa que lo que se practicaba también en otros reinos o imperios vecinos como el austrohúngaro), el cual se había de alguna manera conservado, e incluso renovado, con el régimen comunista y sus políticas de gestión y desplazamientos planificados de población. En cuanto cae el régimen y se abren las fronteras del país, estas minorías fueron las primeras, tanto porque tenían contactos en el extranjero como
} 
gración nacional de los pueblos de cultura y lengua alemana" diseminados por el antiguo bloque comunista, a la cual se añade también una política de asilo claramente favorable hacia todos los "refugiados" del Este. Su actividad consiste esencialmente en pedir estratégicamente el asilo político con el propósito de cobrar las generosas ayudas (en relación con la economía rumana) otorgadas por el Gobierno mientras se estudia el expediente — casi siempre denegadoy volver con pequeñas fortunas al cabo de unos meses. Muchos los imitan hasta que se "satura" el destino y las leyes se hacen más restrictivas (Maisongrande, 2008).

3. Con el cierre progresivo de las fronteras europeas a lo largo de la década de 1990, se interrumpen sus salidas internacionales. Las familias se tienen que dedicar a otras cosas a escala local y regional dentro del país - sobre todo la agricultura y el pequeño comercio al detalle, en el cual numerosos son los que empiezan entonces a profesionalizarse por unos años-. En aquella época, tan solo unos contados individuos intentan y consiguen marchar fuera más allá de Serbia. Son pocos, pero importantes, porque explorarán todo el continente y servirán de "puntas de lanza" para las oleadas siguientes. Esto estructurará los flujos posteriores en el sentido que cada familia o grupo emigrará donde sabe, por estar en contacto con alguno de estos pioneros, que hay oportunidades de trabajo y se les puede ayudar a acceder a ellas (Bleahu, 2004; Pajares, 2007; Baldoni, 2010).

4. En 2002 se abre el acceso al espacio Schengen con visados de turismo de tres meses ( $\sin$ derecho a trabajar), que se aprovechan rápidamente para montar expediciones lucrativas, hacia Francia primero, donde se obtiene dinero de la mendicidad. Es allí donde algunos inventan la técnica de desplazarse de pueblo en pueblo para incrementar sus ganancias con esta actividad, viviendo mientras tanto en sus coches y volviendo a casa cada tres meses. Es también cuando la generación siguiente, los hijos de los primeros migrantes - mayormente veinteañeros que salen del instituto sin oportunidades laborales-, se integra a su vez en estas prácticas. Llega a pasar lo mismo que en Alemania, con una progresiva imitación y competición muy fuerte entre los propios migrantes rumanos que "satura el mercado" (Maisongrande, 2008).

a veces derecho a residencia otorgado desde los países de destino, en salir masivamente a partir de la década de 1990 (Michalon, 2003; Muntele, 2003; Reyniers, 2003; Adler de Lomnitz y Nuche González, 2007). 
5. Es entonces, hacia el 2004-2005, cuando los grupos constituidos en la época anterior, y primero los que tienen contactos allí, se redirigen poco a poco hacia España e Italia, donde hay más trabajo en negro y mejores posibilidades de regularización, principalmente en la construcción y el servicio doméstico. $\mathrm{Al}$ mismo tiempo, los flujos de migrantes (nuevos) desde Rumanía crecen también mucho (Viruela Martínez, 2006; Marcu, 2007). Los espacios de primera concentración de rumanos - Madrid, Castellón, Turín, Florencia-y sus sectores de actividad se saturan a su vez rápidamente, lo que provoca reorientaciones en cascada hacia el sur y las zonas rurales. Allí se aprovechan las reconfiguraciones en curso de la actividad agrícola por las que sustituyen a otras poblaciones locales (que son cada vez menos) e inmigrantes (cada vez más) como mano de obra temporal (Păun, 2006; Şerban, 2006; Hartman, 2008; Maisongrande, 2009).

6. Rápidamente de nuevo, estos espacios rurales se llenan a su vez. Cabe tener en cuenta que la actividad agrícola es por definición incierta y temporal y está marcada por los siguientes factores: 1) la llegada de esta multitudinaria mano de obra inmigrante disponible hace bajar los precios del trabajo en negro; 2) el sector se encuentra en ese mismo momento en un drástico proceso de integración y competencia a escala europea; 3) como consecuencia de esto último, se importan — primero de manera planificada en algunos espacios de producción específicos como Huelva o Lleida y después en prácticamente todos, ya que están en competencia directa - nuevos modelos "modernos" (en el sentido neoliberal) de organización y management del sector ${ }^{9}$, con lo que su organización evoluciona rápidamente hacia un sistema de explotación laboral particularmente duro. Es como adaptación a esto que se establece progresivamente como norma la circulación por todo el continente en busca de trabajos precarios y temporales, entre multitud de espacios conocidos y de actividades

\footnotetext{
9 Se trata del denominado "modelo californiano" de producción basado en: la modernización extrema de esta mediante la inversión masiva realizada por los agricultores (por vía de un endeudamiento igual de masivo); su gestión en "tiempo real" en función de la demanda de los mercados continentales; la fuerte concentración monopolística tanto de las cooperativas como de las centrales de compra al por mayor (que son las que, junto con los bancos prestatarios, sacan el mayor beneficio de todo ello); y el uso y abuso de la subcontratación en cascada del trabajo, que permite reducir al máximo los costes, las incertidumbres meteorológicas y las obligaciones legales que conlleva la propia producción, externalizando todo aquello sobre el último eslabón del sistema, los "nuevos jornaleros", inmigrantes y sin contrato. El resultado final para estos jornaleros agrícolas, en algunas zonas del sur de Europa - resultado prácticamente invisible porque se oculta ampliamente en los pueblos-, son a menudo condiciones de vida y de trabajo muy precarias y con un elevado grado de dependencia material y simbólica respecto a los propietarios agrícolas y sus intermediarios, situación que puede considerarse incluso peor que la de los siervos medievales.
} 
accesibles gracias a los múltiples contactos creados a lo largo de los años de movilidad (Maisongrande, 2010).

Las trayectorias de estos grupos nos dan una idea de lo acontecido en $\mathrm{Ru}$ manía desde la década de 1990. Con la progresiva integración del país (como zona dependiente) en el espacio europeo, la inexorable degradación de las condiciones de vida y el brutal incremento de las desigualdades que esta conlleva, son muchos los que se involucran en este tipo de prácticas de movilidad temporal por todo el continente ${ }^{10}$, tímidamente al principio, pero cada vez más a medida que se asientan las rutas, las actividades y las redes sobre las cuales se basa su explotación (Nacu, 2006; Weber, 2009).

Respecto a esta situación actual, citamos a modo de ejemplo el caso (a principios del 2012, último período de campo) de los miembros de una de las familias cercanas más paradigmáticas del estudio: unos trabajan habitualmente con contrato, aunque no del todo dentro de las normas legales, en la viña en Cognac (Francia), después de haberse dedicado muchos años a la mendicidad por los pueblos de todo el centro-oeste francés; otros todavía se dedican a la mendicidad, pero en España, concretamente en Valladolid, capital donde fueron introducidos por contactos suyos propios y consiguieron "hacerse su hueco" entre el gran número de mendigos rumanos de la ciudad; finalmente, otros trabajan actualmente como jornaleros agrícolas por temporadas entre los pueblos de Sevilla y los del sur de la provincia de Tarragona, donde algunos familiares cercanos (los que mencionábamos al principio) siguen establecidos todo el año.

Todos mantienen el contacto, a distancia o cuando se reencuentran en origen varias veces al año. Colaboran en la migración —intentan puntualmente compartir trabajos o ayudas diversas-, aunque cada uno tiene también sus contactos propios, competencias, destinos y actividades preferentes, según su posición en las redes y su historial personal de movilidad.

Todo depende también de las estrategias individuales y de la posición/ papel de cada uno dentro de la familia. Existe, así, entre ellos una emulación constante para saber, por una parte, quién conseguirá más prestigio personal

10 Se calcula así que unos tres o cuatro millones de personas - es decir, icasi un $20 \%$ de la población total del país!..., y principalmente personas en edad de trabajar- se encontrarían la mayor parte del año en el extranjero. Hoy en día es muy habitual encontrarse por todo el país con zonas prácticamente deshabitadas, tierras agrícolas desatendidas y aldeas donde solo niños y ancianos viven todo el año ya que la principal actividad consiste en salir del país por largas temporadas en busca de cualquier tipo de recursos económicos. 
en la migración ${ }^{11} y$, por otra, quién aportará más de este prestigio a la unidad familiar ${ }^{12}$, en un complejo juego de competición y ostentación que se desarrolla a un nivel superior dentro de la comunidad más amplia, vecinal sobre todo ${ }^{13}$.

\section{¿Qué procesos sociales hay en torno a la migración?}

Más allá de los factores contextuales de tipo más bien macrosocial que las enmarcan y en cierta medida las modelan, las formas que adquieren históricamente las migraciones rumanas responden también a una propia lógica procesual (es decir, evolutiva, según las épocas) que es la que nos interesa aquí tratar de desvelar.

En primer lugar, cabe decir que la actividad migratoria se basa en el uso extensivo y estratégico de las redes sociales.

Es en estas estructuras de interacción social que se producen y circulan las informaciones, las ayudas, las referencias culturales, los conocimientos..., necesarios para poder monitorizar y captar los recursos y las oportunidades disponibles para los migrantes, por escasas, poco rentables o remotas que sean. Así, los efectos de imitación de prácticas migratorias (movilidad y actividades), las adaptaciones frente a múltiples contextos localizados (sociales, laborales, jurídicos...) y los sucesivos fenómenos de saturación de los destinos que provocan las dispersiones exploratorias — que a su vez llevan a las reorientaciones multitudinarias de los flujos ${ }^{14}$ - se explican en buena parte por este "juego" que se desarrolla dentro de las redes sociales de los migrantes (Hily, Berthomière y Mihaylova, 2004; Maya Jariego, 2004; Şerban, 2007).

11 Es decir, saber quién conseguirá (aparentemente) más dinero, sin importar mucho el cómo, siendo las únicas prohibiciones - que estigmatizarían a quien las traspasa y a su familia cercana- la delincuencia (más allá del robo ocasional en las tiendas o de los pequeños trapicheos no muy lucrativos), la prostitución o la explotación excesiva (porque no pasa nada si solo es un poco) de otros miembros de la comunidad. Todo esto, lo que hacen afuera unos y otros y si “está bien" o "está mal", está continuamente a debate en los pueblos de origen y se ha convertido en un objeto más de las tradicionales riñas y cotilleos entre familias, de las interminables luchas simbólicas y de prestigio internas de la comunidad vecinal.

12 Hay que entender aquí la "casa”, los padres, hijos y sus cónyuges que convivían habitualmente antes de empezar a desplazarse y lo vuelven a hacer por turnos y períodos entre dos temporadas en el extranjero.

13 La cual, en Rumanía, por causas socioculturales, históricas y antropológicas muy antiguas, parte de las cuales ya hemos explicado, generalmente coincide con la familia extensa y la comunidad étnica.

14 Y volvemos a evocar aquí la "gran reorientación mediterránea" como referencia. En España, por ejemplo, donde los datos del padrón municipal de habitantes nos dan buena idea de la amplitud y la evolución del fenómeno, la progresión anual del número de nacionales rumanos entre el 2002 y el 2008 es de varios cientos de miles (de unos 70.000 a unos 800.000 ) - muy similar a la que se produce al mismo tiempo en Italia-.

Arxiu d'Etnografia de Catalunya, n. ${ }^{\circ}$ 14, 2014 


\section{Es decir, aparte de que constituyen el soporte necesario de las movilidades} observadas, el mismo funcionamiento interno de las redes y sus evoluciones continuas $^{15}$ influyen directamente sobre la forma de los desplazamientos de sus integrantes en el espacio geográfico. Son, pues, estas las que permiten, a la vez que provocan, el excepcional grado de dispersión y las marcadas pau-

15 Los cambios cíclicos en sus jerarquías de posiciones — de dominación o dependencia- y de oposiciones internas entre individuos o subgrupos dentro de la red; las continuas luchas simbólicas entre distintas prácticas y actitudes en la migración, luchas a raíz de las cuales unas u otras se difunden o prevalecen según las épocas, aportando de paso prestigio y poder a sus individuos o núcleos instigadores y quitándolo a otros; el tejer y destejer continuo de las relaciones y asociaciones preferentes dentro de la red social global... Todas estas cosas, que ocurren constantemente entre las personas incluidas en las redes sociales migratorias y que además suelen influir de manera importante en la trayectoria de todos sus integrantes, raramente provocan cambios visibles en la estructura de las redes y, cuando lo hacen, es mayormente de manera progresiva y con notable antelación o bien retraso respecto a la reconfiguración propiamente dicha de las relaciones (excepto tal vez en situaciones de ruptura repentina y no premeditada de las relaciones como huidas o exilios forzados). Es particularmente esta reflexión sobre la relación entre redes sociales y cambio social y la imposibilidad de entender este último desde una estricta perspectiva de análisis estructural — tal vez recoger sus efectos, pero desde luego no explicarlos - lo que me ha llevado a buscar otros modelos explicativos para este estudio. A continuación detallaré esto un poco más. El modelo de redes ofrece nociones muy valiosas para entender algunas de las propiedades generales de las estructuras sociales, nociones que, como las de continuum, posición intermediaria o transitividad, me han inspirado claramente en mi trabajo teórico para la tesis (Bott, 1957; Boissevain, 1968; Clyde Mitchell, 1974; Menéndez-Carrión, 1985; Wellman, 1997). Sin embargo, el método, usado solo, presenta limitaciones importantes, las principales de las cuales son:

1) No se aplica muy bien a estudios microsociales de grupos muy integrados - migrantes o no- donde todos los individuos mantienen relaciones (links) con todos los otros (conectividad alta). De estas formas estructurales solo nos dice que suelen conllevar un fuerte control social, pero no permite percibir el sentido - en sentido literal y figurado- de este control (quién impone a quién y qué). Pero esto es una crítica general que vale para cualquier tipo de relaciones, ya que el análisis de redes solo se quedan en la parte visible de estas, su existencia o no.

2) La visión que ofrece de las estructuras sociales es estática, únicamente en las formas que presentan en el momento $\mathrm{T}$ de la recogida de datos. Para observar los posibles cambios y sus tendencias, hay que realizar varias recogidas sucesivas, lo que justamente es la línea de algunos estudios recientes sobre redes migratorias que efectivamente observan la existencia de cambios continuos, que además suelen ser cíclicos, pero sin poder explicarlos muy bien (El Bekkari, 2011; Lubbers y Molina, 2014).

Sabiendo lo rápido que pueden cambiar estos aspectos en migración, sobre todo al principio ( $y$ todavía más con las movilidades migratorias que estudio, cortas, repetidas, diversificadas, donde, en cada "época migratoria", cada etapa de las trayectorias personales, cada actividad o lugar de destino, incluso cada viaje o dentro de uno mismo, las redes que sustentan las prácticas de los migrantes pueden evolucionar mucho), solo queda, para recoger completamente las transformaciones y evaluarlas correctamente, realizar un seguimiento prácticamente en "tiempo-real" tanto de las redes como de las movilidades de sus miembros, lo que solo es posible con un grupo reducido de personas. Y, aun así, lo que se consigue es solo una visión, y no una explicación, de fenómenos de cambio - pautados o no- que se deben analizar como correspondencias con los efectos de un modelo teórico más amplio que permita entender la configuración interactiva y procesual de las estructuras sociales (grandes o pequeñas). Y es aquí donde se dio la necesidad de recurrir a Bourdieu. Ahora bien, cabe reconocer también que el enfoque más bien personal que voy poniendo sobre la interrelación también procesual e históricamente contextualizada - entre los campos sociales dentro del conjunto de la sociedad y los procesos de difusión/adaptación sociocultural que se dan entre unos y otros justamente por la acción de los agentes que interactúan y establecen relaciones, entre unos y otros, viene ampliamente inspirado en mis trabajos previos sobre redes sociales. 
tas de movilidad de los migrantes rumanos por todo el continente europeo (Maisongrande, 2008). Pero más allá del análisis descriptivo de estas redes sociales migratorias y de las trayectorias de sus miembros, entender sus lógicas de configuración y reconfiguración histórica requiere centrarse en las propias relaciones entre los agentes que se involucran y se ven involucrados en ellas, que las usan y son usados por ellas, es decir, en sus interacciones simbólicas en, o en relación con, la migración y en los marcos socioculturales específicos que modelan dichas interacciones en cada momento ${ }^{16}$.

Y es el modelo teórico de Bourdieu, sobre todo sus nociones de campo social, lucha simbólica y habitus, el que nos ha parecido el más adecuado para llevar a cabo esta tarea.

En este, cada campo social viene delimitado por la actividad social que define y lo define (el ámbito de relación) y por el universo simbólico e imaginario correspondiente en el cual se posicionan los agentes - por estar formados en él- en el momento de la interacción ${ }^{17}$. Sobre todo considera y constituye un modelo de explicación de cómo la dinámica histórica propia de cada actividad (cada campo social) influye sobre su definición y la estructuración de las posiciones y relaciones de los agentes que se involucran en ella. Tiene en cuenta la relativa interrelación - ella misma estructurada - de todos los campos sociales en el conjunto de la sociedad y cómo determinadas prácticas, representaciones y significaciones pueden solapar a varios de ellos, configurarse en unos para luego difundirse en cascada (o imponerse) en otros, y ser adaptadas. Todo lo cual ocurre primero entre aquellos campos que están en contacto directo (Bourdieu, 1986; 1992) ${ }^{18}$.

16 Lo que justifica también la elección metodológica de centrar y profundizar al máximo el estudio —hasta el nivel psicológico si cabe - sobre un grupo reducido de personas, todos cuyos caracteres y biografía, no solo migratoria, será posible monitorizar y someter a análisis.

17 Los dos mismos agentes en el curso de una misma interacción pueden posicionarse sucesivamente en campos sociales muy distintos $-\mathrm{y}$ adaptar de paso los roles que desarrollan y también sus producciones simbólicas, y con ello acercarse o alejarse uno del otro según su posición estructural respectiva en cada campo-, por ejemplo, cuando una conversación pasa de un tema familiar a un tema político o deportivo. Ahora bien, que los agentes de posición similar en un campo social dado tengan tendencia a compartir también posiciones similares en otros ( $y$, de hecho, frecuentemente en todos) es otra cuestión que justamente se debe fundamentalmente a que todos están interrelacionados — aunque sea mucho más complejo que esto y no lo podamos tratar aquí-.

18 Con sus nociones articuladas de campo social y habitus, Bourdieu trata de examinar la relación circular dinámica entre estructuras socioculturales y conductas (y trayectorias) individuales. Analiza cómo, por su participación activa en actividades culturalmente definidas y estructuradas (campos sociales), los agentes sociales adquieren determinadas pautas — de actuación, de representación y sensibles - correspondientes, 
Estas nociones aplicadas a nuestro objeto de estudio nos llevan, pues, a considerar la existencia de un campo social de la migración rumana, con su habitus correspondiente y sus luchas simbólicas internas. Dicho campo se habría constituido poco a poco en la intersección de otros múltiples campos sociales en origen y destinos de estos flujos, nutriéndose de ellos pero ganando progresivamente su autonomía ${ }^{19}$ y pasando con ello a influir también, cada vez más, sobre estos otros campos.

Y el carácter constitutivo del "campo social de la migración” — rumano, aunque también puede aplicarse a otros- sería jugar un rol de puente, retroalimentación y mezcla, aunque estructurado según sus normas específicas, entre múltiples otros campos sociales, localizados o no. Y, como veremos a continuación con un par de ejemplos, partiendo de esta idea se explican mucho mejor buena parte de los caracteres y las evoluciones, de las lógicas de configuración, de las migraciones observadas.

un habitus que movilizan y articulan "libremente", y sin realmente darse cuenta de ello, en su participación estratégica en estas actividades, pero también en otras. Mediante ambas cosas, son ellos quienes provocan tanto la reproducción (por repetición conforme) como la evolución (por inclusión en cada una y remezcla inventiva con los ya normativos de elementos originados en otros) de todas estas actividades, sus estructuras y pautas correspondientes (que se transmiten de ahora en adelante en la actividad) y de la posición de cada cual en la estructura social global (Castoriadis, 1975; Willis, 1977; Bourdieu, 1979; Vygotsky, 1979; Bourdieu, 1980; Jenkins, 1996).

Todo el proceso en cada una de sus etapas y la variabilidad de sus resultados (la reproducción y/o cambio social) están permitidos por la movilización de símbolos culturales específicos y la articulación de estos, que es la que define sus significados en cada contexto. Son dichos símbolos los que identifican y definen cada ámbito de actividad y la posición de cada uno de estos en la estructura social global. Los participantes de cada campo aprenden a leer y entender los símbolos que corresponden a cada uno, los manejan y producen en su actuación en estos ámbitos, y estos símbolos marcan y establecen también la forma y la posición estructural de su participación en ellos ( $y$ en todos). Pero los agentes pueden también mezclar y adaptar los símbolos que usan tanto en esta actividad como en otras, luchando así en cada una de ellas para imponer o combatir determinados significados simbólicos, obteniendo así, perdiendo o manteniendo, un estatus simbólico que viene ligado a diferentes tipos de gratificaciones que pueden después reinvertir exitosamente en otros ámbitos (capital simbólico). Al hacerlo, modifican o defienden el sentido de la actividad que se define en cada ámbito, y a continuación la actividad propiamente dicha, modifican o defienden la estructuración de esta y su posición personal en ella, modifican o defienden las pautas culturales que le corresponden y que se adquieren en ella y las mismas articulaciones simbólicas que produce la actividad y la identifican, modifican o defienden por fin la posición ocupada por la actividad (el campo) en la estructura social global y la suya personal de paso (y los símbolos estatutarios correspondientes, con sus gratificaciones) (Berger y Luckmann, 1966; Turner, 1967; Bourdieu, 1980; Elias, 1989; Bourdieu, 1996; Elias, 2000; Bourdieu, 2001).

19 Con lo cual pasa principalmente a definirse, estructurarse, (re)producirse y simbolizarse por sí mismo y en interno. Y, efectivamente, en el caso del campo social de la migración rumana, dispone de figuras culturales propias y distintivas, algunas de las cuales analizaremos en la tesis (la del Şmecher, particularmente). 


\section{Algunos avances de análisis}

\section{Actividades}

Las primeras fases de las migraciones del grupo estudiado se centraban, pues, en el pequeño comercio transfronterizo y en la petición de asilo a países occidentales, que implicaban una fuerte movilidad y pluriactividad. Se asemejaban a una reproducción/adaptación libre de pautas ya desarrolladas previamente (y documentadas) por otras poblaciones del este de Europa durante las décadas anteriores, las cuales se habían progresivamente asentado bajo estas formas concretas. Este era, pues, el estado histórico del campo de la "migración del este de Europa” en el momento en que los rumanos se integran en él a partir de 1990 (Blaschke, Simon y Costa-Lascoux, 1991; Morokvasic, 1996).

Por una parte, estas pautas eran las más sencillas de reproducir por ser las más fácilmente accesibles, pero también perceptibles y comprensibles por los rumanos. Habían sido desarrolladas por poblaciones cercanas a ellos (serbios y polacos sobre todo), con las cuales estaban ya en contacto y con las cuales compartían, en el fondo, buena parte de los caracteres estructurales y de las referencias socioculturales "de origen" que habían podido influir en la configuración del fenómeno ${ }^{20}$. No distaban tampoco mucho de las pautas de combinación de movilidad y actividades variadas que ya eran "casi tradicionales" en los pueblos de la Rumania comunista e incluso antes (aunque solo a escala nacional).

Por otra, y esto es mucho más decisivo tal vez, porque, al ostentar los rumanos en sus primeros espacios sociales de destino unas "etiquetas simbólicas" parecidas a las de sus predecesores, fueron percibidos como iguales. Se actuaba con ellos del mismo modo, se reproducían en las interacciones con ellos los mismos símbolos que activaban en retorno reacciones percibidas como similares, lo cual venía en conjunto a dirigirles inconscientemente hacia los mismos canales y roles (preconstituidos y asimilados bajo esta forma por las poblaciones de acogida en relación con los migrantes anteriores) y hacia las mismas actividades. Al tener que adaptarse a estas coerciones simbólicas, los migrantes rumanos adoptaron las actitudes, prácticas y representaciones correspondientes, desarrollaron estrategias similares y acabaron pareciéndose objetivamente más a estos otros inmigrantes con quienes se les confundía — no solo a causa de

20 Entre otras cosas, esta larga experiencia del mercado negro y de los "chanchullos" típicos del comunismo tardío del este de Europa. 
una similitud de caracteres originarios entre unos y otros, sino más bien debido al trato indiscriminado que se les daba- (Marc y Picard, 1992; Lipiansky, 1993; Santamaria, 2002).

Una vez integradas estas primeras asignaciones, los rumanos las iban a reproducir en su práctica migratoria. Podían también empezar a jugar con ellas y adaptarlas, en su caso.

Un buen ejemplo de ello son las primeras migraciones de grupos de minorías étnicas rumanas hacia Alemania y la "carrera" de demandante de asilo político hacia la cual se ven canalizados — siendo allí el trato habitual que se daba a los refugiados del Este (no alemanes) - , cuando la gran mayoría de ellos no se correspondían para nada con el perfil de refugiado: desconocían en gran medida esta posibilidad jurídica al principio y tampoco se ajustaba a lo que buscaban en la migración ${ }^{21}$. Por lo tanto, era previsible que acabaran por desviar en su provecho el espíritu y la práctica de la demanda de asilo, convirtiéndola en lo que venían buscando, una actividad temporal/ocasional y rentable a corto plazo. Esta primera experiencia será, sin embargo, fundadora de la migración rumana al ser el primer contacto directo que muchos de ellos - la gran mayoría nunca habían salido antes del país - iban a tener con el "Occidente mitificado" - que resultó ser esencialmente dominador, pero al cual se podían "adaptar"-

Lo que habían aprendido allí, este rol específico de "refugiado" — definido como tal en las instituciones de acogida y por los trabajadores sociales, que constituían también una suerte de campo social identificable por unas prácticas y unos imaginarios correspondientes ("humanitarios")—, lo habían asimilado colectivamente, no sin dificultad, e incluido progresivamente en sus constructos cognitivos. Por deducciones y mimetismo, ensayos sucesivos y rectificándose unos a otros, habían mejorado su habilidad a la hora de desempeñarlo e improvisar con él. De su capacidad para conseguirlo dependía el éxito de su proyecto migratorio. De vuelta a casa, para explicar esta primera experiencia a sus familiares y amigos y que estos la entendiesen, la tuvieron que traducir en los lenguajes simbólicos de sus grupos de origen, buscando, por ejemplo, correspondencias entre estas nuevas experiencias y las que habían sido las propias de todo el mundo con las instituciones comunistas. Con esto, provocaban

21 La idea en aquel entonces era más bien "salir a la aventura", intentando de paso realizar algún buen golpe para mejorar la situación en casa, según el modelo que ya se observaba con polacos y serbios; nada que ver con exiliados perseguidos que buscan establecerse definitivamente fuera de su país de origen y dejándolo todo atrás. 
también la difusión de las representaciones y los roles nuevos - no tanto en el fondo- que habían adquirido, haciéndolos para todos más fáciles de reproducir y adaptar incluso por aquellos que no habían podido participar en estas expediciones alemanas (es decir, también sus conocidos rumanos no gitanos que no habían tenido acceso a ellas por un tema jurídico de libre circulación vía Polonia).

Todo esto, que pasa a formar parte del novedoso campo social de la migración rumana y de su habitus en formación, lo volvemos a encontrar lógicamente durante sus siguientes fases de movilidad. Así se entiende cuáles son los resortes del imaginario cultural de las sociedades occidentales de los que se aprovecharon, cuáles fueron las correspondencias estructurales pero también simbólicas fáciles de percibir y de producir que, muy probablemente y sin menospreciar la importancia de otros factores (mayormente jurídicos), favorecieron el traslado de esta primera actividad hacia la mendicidad y, concretamente, el tipo de mendicidad que practicaban los rumanos en Francia.

Con sus formas de practicar la mendicidad trataban de jugar con las representaciones de la miseria y la indigencia "digna", dando pena sin dar asco, para un público que habían aprendido a conocer durante sus primeras circulaciones, y después de un período de formación que les había sido impuesto pero que supieron adaptar, "llevándolo a la calle". Por ello, movilizaban toda clase de símbolos positivamente valorados como la familia (incluso con fotos, para que quede claro), la voluntad de luchar para salir de la pobreza, la constancia... Trataban de ser siempre educados, afables y limpios, y así se diferenciaban claramente de los mendigos habituales — tradicionalmente asociados a nociones negativas como la bohemia, la pereza y el rechazo al trabajo, la dejadez, el alcoholismo...-. En resumen, "jugaban" su papel, abrazaban su posición dominada y, con ello, contentaban a su público, obteniendo con ello beneficios muy superiores (Diminescu, 1999; Potot, 2003).

Y si enfocamos el problema en el terreno de la pura y dura "rentabilidad de la expedición circulatoria"22, tal como lo hacían los propios rumanos porque era

22 Aquel elemento vuelve constantemente en sus discursos y queda más evidente todavía si consideramos sus prácticas de ahorro extremo en la migración: yendo sistemáticamente en sus gastos cotidianos a lo más esencial y lo más barato, prohibiéndose prácticamente cualquier tipo de gasto de ocio, mostrando poco interés por la "calidad" de sus condiciones de vida — como lo de vivir en chabolas, pisos-patera o en sus coches durante largos períodos de tiempos- por poco que les permita incrementar un poco sus ganancias finales... Este carácter parece, además, ser muy específico del campo social de la migración en el sentido que no tiene 
constitutivo de su "habitus migratorio", vemos aparecer más claramente lo que estas formas propias de ejercer la mendicidad debían a la otra gran actividad asimilada en el campo social de la migración: el pequeño comercio de compraventa, que muchos habían practicado o seguían practicando habitualmente entre dos viajes a Francia.

El "modo rumano" de ejercer la mendicidad se había asentado progresivamente bajo esta forma por imitación, invención y ensayos sucesivos. Implicaba: 1) la identificación de una actividad potencialmente rentable como la de ofrecer la posibilidad de "ejercer la caridad", pero poco aprovechada por los mendigos nacionales (ni tan motivados ni tan buenos para venderse y que rápidamente se ven fuera del negocio); 2) la aplicación de métodos casi profesionales que incluían la organización racional de la actividad por sectores, turnos y funciones diferenciadas; 3) un marketing innovador —un trozo de cartón, con o sin foto, explicando una historia personal inventada-; 4) la búsqueda y el establecimiento de nuevos mercados como cuando los mendigos empiezan a desplazarse hacia el interior del país yendo de pueblo en pueblo. Tenemos aquí algo que se asemeja a una adaptación dual, una reproducción combinada de las experiencias asimiladas, por una parte, y, por otra, en el campo social migratorio, entre la carrera de asistido social y el espíritu empresarial de los pequeños comerciantes, justamente las dos actividades primigenias de las movilidades migratorias rumanas.

Y si resulta difícil percibir la lógica de esta evolución, incluso y sobre todo por los propios migrantes que la produjeron, es que más que siendo resultado propiamente de una planificación consciente o de una imposición estructural, corresponde más bien a una "improvisación libre" — eso sí, fuertemente enmarcada por determinaciones socioculturales que se desconocen como tales-, a la expresión de un habitus.

No seguiremos aquí con este análisis de la actividad de los migrantes rumanos y de sus evoluciones puesto que solo se trataba de ver lo que puede ofrecer el modelo del campo social y del habitus a este tipo de estudios. Presentaremos otra reflexión, de corte más estructural, sobre el papel de factor de integración y evolución en cascada que parece jugar el campo social migratorio rumano entre múltiples espacios físicos y sociales a lo largo y ancho del continente europeo.

nada que ver con sus prácticas durante sus vueltas periódicas en origen, de despilfarro de ostentación el más completo y/o de inversión casi exclusiva de sus ahorros en la construcción o mejora de sus casas. 


\section{Estructuras}

Las influencias cruzadas y a veces contradictorias que recibe constantemente desde otros campos este "campo social de la migración" (el de estos grupos migrantes) dan lugar a una tensión, inherente a su posición intermediaria, que es en parte causa, pero también síntoma, de la intensa lucha simbólica que se desarrolla en su seno y de la cual se pueden detectar efectos visibles en su estructura.

Volviendo de nuevo al principio de la constitución del campo, se puede lógicamente pensar que, en un primer momento, su forma tenía que ver más con las estructuras socioculturales de los campos sociales con los cuales se cruzaba en origen de los flujos que no en destino. Se sabe así que las primeras salidas migratorias de los rumanos fueron principalmente colectivas y estuvieron fuertemente marcadas en su organización por el criterio de pertenencia comunitaria/étnica — como en el caso de los gitanos de las aldeas estudiadas, que se fueron a centenares, y solo ellos, a Alemania-. Estos flujos parecían, pues, muy acordes con la mezcla de comunismo colectivista y de estructuras clientelares tradicionales y etnicizadas que prevalecían en aquella época en Rumanía (Amselle, 1992; Rey, 2003).

Después, con el paso de los años, vemos como este doble carácter sigue siendo específico de las migraciones rumanas, aunque en estado latente, si bien sigue expresándose periódicamente: con las grandes reorientaciones colectivas sucesivas a lo largo de su historia o con los desplazamientos ya habituales de miles de personas para las cosechas agrícolas en el sur de España e Italia y la gestión claramente clientelista de estas (con sus patrones, intermediarios, captadores y "gañanes", y todos sus "clientes" pidiéndoles días de trabajo).

Por otro lado, se observa también que, fuera de estos episodios recurrentes de recolectivización repentina de la migración ${ }^{23}$, sus movilidades se estructuran esencialmente, y tal vez cada vez más, sobre la base de criterios individuales o de familia nuclear/cercana.

Algo parecido ocurre en las aldeas de origen, donde, por imitación y ayudas anteriormente aportadas por las redes, prácticamente todas las familias vecinas están ahora involucradas en la migración y se han beneficiado de ella. Todo

23 E incluso dentro si miramos cómo durante estas etapas de migración colectiva se organizan, principalmente por familias nucleares, la puesta en común de los gastos y las ganancias, la economía familiar y las compras, los proyectos de inversión, la preparación y toma de las comidas, etc. 
el mundo insiste en que, respecto a la situación de hace 10 o 15 años, se nota entre vecinos un fuerte incremento de los celos y de los juegos de ostentación (cotilleos dañinos, recelo entre familias que puede llegar hasta la franca hostilidad, robos en casas...), mientras que parecen debilitarse progresivamente la solidaridad aldeana y las prácticas de ayuda mutua incluso durante los rituales colectivos en los cuales se reafirmaban tradicionalmente. Y esto influye a su vez sobre las migraciones al reforzar la tendencia de estructuración del campo en torno al exclusivo criterio de familia nuclear/cercana. Estas familias, a lo largo de los años de movilidad, van centrando progresivamente sus relaciones preferentes en las redes sociales migratorias en alianzas externas a la comunidad local - sobre todo con las familias de los cónyuges, que suelen ser de otros pueblos de la zona, lo cual refuerza la integración de conjunto a escala regional-.

Frente a estas evoluciones, una primera reflexión sería simplemente decir que nos encontramos frente a un sencillo fenómeno de "modernización" de las estructuras socioculturales por difusión. Un proceso gradual en el cual tendríamos un "modelo comunitario tradicional" que se encontraría históricamente, con las migraciones, en contacto con el "individualismo occidental moderno", al cual le estaría dejando paso poco a poco, con las dudas, des-integraciones y conflictos que esto puede suponer. Y aquí el campo migratorio constituiría el vector privilegiado de la difusión sociocultural.

Aunque no sea del todo falso, la realidad no es tan sencilla y solo se puede entender si se considera que - dentro de una tendencia general que sería efectivamente la de una imposición global de los criterios occidentales - la forma que toma dicha difusión en cada caso depende ampliamente de la retroalimentación compleja y nada lineal de los campos sociales que se encuentran así puestos en contacto. Aquí solo daremos unos elementos muy generales.

Según el modelo evocado más arriba, parece así factible que los migrantes, que están habitualmente en contacto con campos sociales de destino donde se les considera más estrictamente bajo el ángulo del individuo o de la familia nuclear (sobre todo en el trabajo y frente a las instituciones), acaben por adquirir, reproducir y difundir, inconscientemente, estos criterios en sus percepciones, prácticas, valoraciones y producciones simbólicas, primero en estos mismos campos — donde es condición de su integración exitosa-, después en la mi- 
gración y, finalmente, en origen ${ }^{24}$. Con los recursos simbólicos que adquieren en la migración (económicos y de prestigio) y que pueden reinvertir en sus campos sociales de origen (la ostentación simbólica), su estatus en estos suele progresar también, al conllevar que se vuelvan más poderosos en las luchas simbólicas, que tengan más peso a la hora de marcar pautas, justamente estas pautas "modernas" - siendo, además, apoyados en ello por otras tendencias actuales de la sociedad rumana en general ${ }^{25}$-.

Su relativo alejamiento (físico) de lo que constituye el día a día de las luchas simbólicas en origen, además de sus dificultades para objetivarlas o integrarse en ellas en posiciones que no sean las que estructuralmente les corresponden y tienen marcadas en su "babitus aldeano" (al haber sido socializados primariamente en dichas luchas), su peso "en un sentido de cambio" en los procesos de reproducción social aldeana no es tan fuerte como se podría suponer ${ }^{26}$. Y si efectivamente notamos que hay retroalimentación, que hay algo de los criterios de estructuración sociocultural de campos sociales de destino que pasa a los de origen, esto nunca sería posible, no "cuajaría", de no corresponder a tendencias y representaciones que ya existen, aunque de forma diferente, en la cultura tradicional rural que todavía prevalece ampliamente en las aldeas rumanas.

Dicho de otro modo, lo que se observa en los espacios de origen no es tanto una imposición unilateral del individualismo occidental como una suerte de

$24 \mathrm{Y}$ tenemos que señalar aquí el grave abuso que constituiría considerar que las sociedades occidentales están completamente dominadas por el principio individualista-moderno e ignorar que en ellas - en cada campo social de manera específica, pero también entre ellos- se desarrolla una lucha simbólica constante (lejos de estar resuelta) en la cual esta oposición tradición/modernidad-individuo/comunidad es justamente una de las más antiguas y centrales.

25 Con la imposición desde arriba, como corolario de la integración europea y global, del capitalismo neoliberal y de todo su imaginario de consumo, ocio y competición individual, que todavía podría resumirse en la imagen de la arquetípica "familia norteamericana de clase media" que vemos aparecer en tantos anuncios y series televisivas de aquí y allí.

26 Lo que se observa claramente durante las vueltas periódicas en origen, cuando, por muy alejadas de sus preocupaciones diarias en la migración que puedan estar las luchas simbólicas internas a la comunidad vecinal (a veces en total contradicción), los migrantes vuelven "natural" y automáticamente a integrarse en ellas, eso sí, con todo el peso simbólico y todos los recursos que han podido nuevamente adquirir. Lo hacen, además, en las que siempre han sido sus posiciones en estas, retomando sin casi ningún cambio ni perspectiva los roles, las prácticas y los marcadores simbólicos de afiliación/oposición que, en relación casi exclusiva con la estructuración sociocultural local, les corresponden: como padres, hijos o esposas, miembros de su "casa"... - con todo lo que dichas posiciones podían tradicionalmente conllevar y siguen conllevando, sin que haya habido mucho cambio, ya que todo el control social familiar/comunitario (buena parte del cual pasa por los afectos, a los cuales son muy receptivos ya que se han criado en estas familias y estos pueblos) converge para que así sea-. 
fusión por correspondencias (simbólicas) entre lo que se ha podido adquirir de este y la más tradicional competición interna en la comunidad entre "casas" y linajes de primos-hermanos. Esta siempre ha sido constitutiva de la cultura rural rumana ${ }^{27}$, y se reactiva y refuerza por estas intervenciones exteriores, incluso se nutre, integra y se "apodera” progresivamente de la práctica migratoria, usándola como recurso para su propia reproducción. Desde una perspectiva de lucha simbólica "entre campos sociales" (practicados simultáneamente por los mismos agentes), parece que el de la migración principalmente estaría infeudado a, e instrumentalizado por, otros más propios de la sociedad de origen. Así, en las prácticas y elecciones estratégicas de los migrantes, las lógicas familiares/ comunitarias definidas en origen se imponen generalmente a la "racionalidad migratoria individual" (o como mínimo se tienen que poder presentar simbólicamente como respetuosas de aquellas, para evitar las sanciones simbólicas).

Así, en realidad, ambas cosas, que podríamos denominar como "la estructuración comunitaria tradicional" y el "individualismo (semi)moderno-capitalista”, se aprovechan mutuamente para su reproducción/difusión y se retroalimentan, configurando poco a poco un nuevo sistema integrado. A pesar de la total oposición en la cual se las presenta habitualmente, no lo podrían hacer de no existir, entre la una y la otra, convergencias de todo tipo que hacen posible esta fusión progresiva que vemos acontecer ${ }^{28}$.

Y el punto de encuentro/confrontación de estas tendencias se situaría, hoy y para estos grupos, específicamente en el campo social de la migración, siendo

27 Aunque aquí tampoco se puede detallar, cabe decir que sus raíces se encuentran en el propio sistema antropológico tradicional campesino rumano, en las pautas de alianzas matrimoniales exógenas patrilocales que son allí norma desde tiempos inmemorables y que habían sobrevivido a — porque también, como hoy sucede con las migraciones, habían sabido fusionarse con ellas - la colectivización y la planificación autoritaria comunista (Amselle, 1992; Todd, 2011). Estas pautas todavía vigentes, las cuales provocan al fin y al cabo que las aldeas ( $y$ sus barrios respectivos) estén casi exclusivamente pobladas por familias emparentadas por rama paternal, explican en buena medida que la sociedad rumana mantenga hasta hoy altos grados de clientelismo y etnicización.

28 Y se olvida a menudo — más bien se oculta - que fue a partir de estructuras antropológicas y socioculturales campesinas esencialmente parecidas a las que observamos en plena transformación en Rumanía hoy en día que también se asentaron y configuraron históricamente el capitalismo y la modernidad en Europa occidental, retomando de ellas numerosos elementos estructurales y culturales preestablecidos, a partir de los cuales evolucionaron después de manera específica, pero conservando y reproduciendo, hasta hoy, buena parte de esta herencia, que encontramos todavía ocupando las posiciones más centrales de su imaginario (el patriarcado y la dominación - masculina y otras-, la solidaridad familiar y los afectos normativos que la mantienen, el clientelismo en los grupos de identificación y sobre todo familiares, las nociones de filiación y de herencia, o hasta la propia idea nacional..., todos ellos elementos que, lejos de ser "naturales", son en realidad restos o adaptaciones de conceptos ya centrales en época medieval e incluso antes). 
esto muy visible para las personas que hemos podido seguir a lo largo de los años: en sus trayectorias de movilidad espacial y sociolaboral, en sus discursos, prácticas, proyecciones y, cómo no, en la estructuración cambiante de sus redes sociales. Y en cada ámbito y en cada etapa del proceso, en las trayectorias de movilidad a veces erráticas, en los repetidos ensayos y rectificaciones de actividades y de asociaciones en las redes, en las prácticas y producciones simbólicas sucesivas pero contradictorias..., siempre encontramos esta articulación dual y esta tensión ${ }^{29}$, en definitiva, esta lucha simbólica y cognitiva constante entre aquellos dos principios de generación de prácticas, estrategias y producciones simbólicas en el campo social migratorio: el colectivo/comunitario y el indivi$\mathrm{dual} /$ nuclear. Y todo pasa como si, en las interacciones sociales y en las mentes, cada cual a su vez tomara ventaja sobre el otro, tuviera momentáneamente prioridad en el campo, haciéndolo así evolucionar. Vemos así que los fenómenos cíclicos de "respiración" (agrupación/saturación/dispersión) que detectábamos en las redes sociales y las movilidades migratorias parecen tener raíces mucho más profundas que las meras causas materiales en destino de las cuales parecían ser efecto.

Podemos, pues, empezar a deducir que este fenómeno, que no sin razón nos recuerda a la dualidad entre Gesellschaft y Gemeinschaft de la sociología clásica, encuentra sobre todo sus raíces en los campos sociales con los cuales el campo social de la migración se cruza tanto en origen como en los destinos de los flujos. Este mismo campo social migratorio, al pasar a ser portador de esta oposición y reproducirla en su seno, la difunde a su vez en todos, alimentando con ello el proceso de integración entre unos y otros ${ }^{30}$.

\footnotetext{
29 Entre pero también dentro de los agentes, con todas las dudas y el sufrimiento emocional que esto puede suponer.

30 Otro ejemplo de las mismas lógicas que quería señalar sería la —muy discutible - distinción sociocultural entre rumanos gitanos y no gitanos. Descubierta progresivamente en Occidente, en parte por medio de las migraciones, pasa a ser muy comentada (aprovechada) en ciertos campos sociales de destino, en ciertos círculos (políticos, académicos, periodísticos, etc.), donde toma una connotación mucho más étnica y esencialista que la que tenía originalmente allí. Es bajo esta forma que es luego reintroducida a su vez en algunos campos sociales de origen - aprovechada también, siguiendo un modelo claramente neocolonial perfectamente descrito en los excelentes trabajos de Nacu一, aun y cuando había, mientras tanto, perdido casi toda realidad - a pesar de seguir utilizándose habitualmente como arma simbólica, de definición extremadamente vaga, en toda clase de luchas simbólicas entre rumanos - en muchos ámbitos de la vida cotidiana en el país, muy notablemente entre los agentes involucrados en el campo social de la migración (ya que iba mayormente en contra de la lógica propia de este de aprovechar todos los contactos disponibles) (Nacu, 2006; Maisongrande, 2012; Olivera, 2012).
} 
De nuevo, dejaremos la reflexión en este punto ya que aquí solo queríamos presentar el funcionamiento del modelo y concretar algunos caracteres de este campo social de la migración. Con estos dos ejemplos podemos ver el tipo de desarrollos analíticos que permite el uso de esta noción. Y más allá del caso específico de las migraciones rumanas, postulamos que puede constituir una respuesta interesante a importantes preguntas, y muy actuales, dentro del ámbito más amplio de los estudios migratorios y/o transnacionales en general ${ }^{31}$. Queda todavía por definir mucho mejor este objeto conceptual —además, para el artículo tuve que simplificar y sintetizar su aplicación tal vez más de la cuenta-, lo que intentaré en la tesis doctoral, utilizando para ello el ejemplo específico de las migraciones rumanas y la gran suma de datos etnográficos recogidos y que quedan todavía por analizar.

31 Muchos otros autores que trabajan sobre migraciones ya intentaron antes movilizar las nociones de Bourdieu de campo social y habitus (Morokvasic, 1999; Tarrius, 2001; Levitt y Glick Schiller, 2004; Suárez Navaz, 2007; Vertovec, 2009; entre otros). Aunque sería claramente necesario para la tesis, no haré aquí ningún repaso crítico a la literatura existente, y en ella, a los usos (o intentos) que se han podido hacer de estos conceptos. El simple hecho de que no haya citado hasta ahora, en la última nota, los trabajos de ciertos autores, algunos de los cuales muy famosos, acerca de estas nociones y su posible aplicación para los "estudios transnacionales" - adjetivo que tampoco he usado-, ya dice mucho de mis dudas al respecto. No es ningun misterio que el modelo teórico de Bourdieu es muy complejo ya que el propio autor - que era un trabajador insaciable - dedicó toda su carrera académica a tratar de definirlo. Su obra, como su manera de escribir en francés, no es fácil de abordar y, a pesar de llegar a ser muy famosa internacionalmente, tengo la sensación de que no siempre ha sido correctamente entendida ni traducida (particularmente al inglés). Me parece, sin embargo, que tiene un gran poder explicativo, particularmente valioso en el caso de las migraciones, que intentaré humildemente, y necesariamente con algunas adaptaciones que espero no serán abusivas, poner a contribución para este estudio. 


\section{Bibliografia}

Adler de Lomnitz, L. y Nuche González, A. (2007): "Migración campesina de una sociedad post-comunista hacia la Europa capitalista: El caso de la etnia Csángó de Moldavia”. Adler-Lomnitz, L. y Nuche González, A. (2007): "Peasant Ethnic Migration from a Post-communist Society to Another. The Case of the Csángó Migrants from Moldavia (Romania) to Hungary". Review of Sociology, (13)1: 67-88.

Amselle, J. L. (1992): "La corruption et le clientélisme au Mali et Europe de l'Est: Quelques points de comparaison". Cabiers d'études africaines, 32 (128): 629-642.

Baldoni, E. (2010): "La migración de Rumanía: Nuevos y antiguos escenarios para la movilidad". Obets. Revista de Ciencias Sociales, 5 (2): 175-199.

Berger, P. y Luckmann, T. (1966): La construcción social de la realidad. Buenos Aires: Amorrortu Editores.

Blaschre, J*; Simon, G. y Costa-Lascoux, J. (1991): "Les travailleurs étrangers dans l'Allemagne réunifiée". Revue Européenne des Migrations Internationales, 7 (2): 63-82.

Bleahu, A. (2004): "Romanian migration to Spain. Motivation, networks and strategies". En Pop, D. (ed.): New Patterns of Labour Migration in CEE. Cluj-Napoca: AMM Design: 21-35.

Boissevain, J. (1968): "The place of non-group in the social sciences". Man, new series, 3 (4): 542-556.

Вотт, E. (1957): Family and social networks. Roles, norms and external relationship in ordinary urban families. Nueva York: Mac Millan Company.

Bourdieu, P. (1979): La distinction. Critique sociale du jugement. París: Les éditions de minuit.

- (1980): «Le capital social. Notes provisoires». Actes de la recherche en sciences sociales, 31:2-3.

- (1980): Le sens pratique. París: Les Éditions de Minuit.

- (1986): «Habitus, code et codification». Actes de la recherche en sciences sociales, 64: 40-44.

- (1992): Les règles de l'art. Genèse et structure du champ littéraire. París: Éditions du Seuil.

- (1996): Raisons pratiques. Sur la théorie de l'action. París: Seuil. 
- (2001): Langage et pouvoir symbolique. París: Éditions Fayard.

Castoriadis, C. (1975): L'institution imaginaire de la société. París: Éditions du Seuil.

Clyde Mitchell, J. (1974): "Social Networks”. Annual review of anthropology, 3: 279-299.

Diminescu, D. (1999): "Faire une saison. Pour une anthropologie des migrations roumaines en France. Le cas du pays d'Oas". Migration Études, 91: 16.

El Bekkari, A. (2011): “La família i l’ètnia en les xarxes socials personals dels migrants: el cas de migrants sirians a Barcelona”. Arxiu d'Etnografia de Catalunya, 11: 179-195.

Elias, N. (1989): Teoría del símbolo. Un ensayo de antropología cultural. Barcelona: Ediciones Península.

- (2000): La sociedad de los individuos. Barcelona: Ediciones Península.

Hartman, T. (2008): "States, markets, and other unexceptional communities: informal Romanian labour in a Spanish agricultural zone". Journal of the Royal Anthropological Institute, 14: 496-514.

Hily, M. A.; Berthomière, W. y Mihaylova, D. (2004): "La notion de 'réseaux sociaux' en migration". Hommes E migrations, 1250: 5-12.

Hily, M. A.; Doraï, K. y Ma Mung, E. (1998): "La circulation migratoire. Bilan des travaux". Migrations Etudes, 84: 12.

Jenkins, R. (1996): Social identity. Londres-Nueva York: Routledge.

Levitt, P. y Glick Schiller, N. (2004): "Perspectivas internacionales sobre migración: Conceptualizar la simultaneidad". Migración y Desarrollo, segundo semestre 2004: 60-91.

Lipiansky, E. M. (1993): "Lidentité dans la communication". Communication et langages, $97: 31-37$.

Lubbers, M. J. y Molina, J. L. (2014): “Realidades enredadas: La negociación de identidades y el sentido de pertenencia dentro de un contexto transnacional”. XIII Congreso de Antropología, Tarragona.

Maisongrande, V. (2008): "Les circulations migratoires roumaines en Europe: Réseaux sociaux et inscription dans l'espace”. Memoria de Máster II. Poitiers: Migrinter.

- (2009): "La movilidad de los rumanos en España: Análisis espacial y estadística a nivel de municipios”. XII Congreso de Inmigración, Universidad de Almería. 
- (2010): "Evolución de las inmigraciones rumanas en España. ¿Hacia un aumento de las circulaciones hacia los espacios rurales?". En De CAstro PeRICACHo, C. (ed.): Mediterráneo migrante: tres décadas de flujos migratorios. Murcia: Editorial de la UM. 57-72.

- (2012): "Migrations Rroms de Roumanie: Vers une modification des rapports sociaux intercommunautaires liée aux migrations internationales?”. En Le Marcis, F. y Lurbe I Puerto, K. (eds.): Endoétrangers. Exclusion, reconnaissance et expérience des Rroms et gens du voyage en Europe. Louvainla-Neuve: Harmattan Academia. 55-82.

Marc, E. y Picard, D. (1992): Interacción social. Cultura, instituciones y comunicación. Barcelona: Editorial Paidós.

Marcu, S. (2007): “Dinámica y estructura migratoria laboral de los rumanos: 1990-2006. Flujos de emigración hacia España, destino Madrid”. Migraciones, $21: 115-157$.

Maya Jariego, I. (2004): "La formación de comunidades de inmigrantes: Desplazamientos en cadena y contexto de recepción”. Araucaria, 5 (12): 83-91. Menéndez-Carrión, A. (1985): The 1952-1978 presidential elections in Ecuador and Guayaquil's suburbio: A micro-analysis of voting behavior in a context of social control. Baltimore: Johns Hopkins University.

Michalon, B. (2003): "Migrations des Saxons de Roumanie en Allemagne: mythe, interdépendance et altérité dans le retour". Tesis doctoral. Universidad de Poitiers.

Morokvasic, M. (1996): "Entre l'Est et l'Ouest, des Migrations Pendulaires". En Morokvasic, M. y Rudolph, H. (eds.): Migrants, les nouvelles mobilités en Europe. París: L'Harmattan. 119-157.

- (1999): «La mobilité transnationale comme ressource: le cas des migrants d'Europe de l'est». Cultures et Conflits, 33-34: 105-122.

Muntele, I. (2003): "Migrations internationales dans la Roumanie moderne et contemporaine". En Diminescu, D. (ed.): Visibles mais peu nombreux...: Les circulations migratoires roumaines. París: Editions de la Maison des Sciences de l>Homme. 33-49.

Nacu, A. (2006): "La construction sociale de la pauvreté en Roumanie et en Bulgarie après 1989”. Tesis doctoral. Institut d'Études Politiques de París.

Olivera, M. (2012): "Les Tsiganes comme autochtones. Le cas des Roms Gabori-Roumanie". Balkanologie, 14(1-2): 10 . 
Pajares, M. (2007): Inmigrantes del Este. Procesos migratorios de los rumanos. Barcelona: Icaria.

Păun, G. (2006): «Mitul străinătății la Năneşti-Vrancea». En SANdu, D. (ed.): Locuirea Temporară în străinătate. Migrația economică a românilor: 19902006. Bucarest: Fundația pentru o Societate Deschisâ. 107-118.

Ротот, S. (2003): "Circulation et réseaux de migrants roumains: Une contribution à l'étude des nouvelles mobilités en Europe". Tesis doctoral, Universidad de Nice-Sophia Antipolis.

RAdu, Co.y RADu, C. (2006): "Românii Câştigă bani europeni cu vize la sârbi”. En SAndu, D. (ed.): Locuirea Temporară în străinătate. Migrația economică a românilor: 1990-2006. Bucarest: Fundația pentru o Societate Deschisâ. $127-148$.

Rey, V. (2003): “Les Roumains sur les chemins de l'Europe”. En Diminescu, D. (ed.): Visibles mais peu nombreux...: les circulations migratoires roumaines. París: Editions de la Maison des Sciences de l'Homme. 28-32.

Reyniers, A. (2003): "Migrations tsiganes de Roumanie”. En Diminescu, D. (ed.): Visibles mais peu nombreux...: les circulations migratoires roumaines. $\mathrm{Pa}$ rís: Editions de la Maison des Sciences de l'Homme. 51-63.

Sandu, D.; Radu, C.; Constantinescu, M. et alii (2004): A country report on Romanian migration abroad: Stocks and flows after 1989. Praga: Multicultural Center.

Santamaria, E. (2002): La incógnita del extraño. Una aproximación a la significación sociológica de la "inmigración no comunitaria". Rubí: Anthropos Editorial.

Şerban, M. (2006): “Trasee de migrație internațională către Spania”. En SANDu, D. (ed.): Locuirea Temporară în străinătate. Migrația economică a românilor: 1990-2006. Bucarest: Fundația pentru o Societate Deschisâ. 119-126.

- (2007): "Mecanismos de desarrollo de la migración a nivel de comunidad: Redes de migrantes y tipos de vínculos". Migraciones, 21: 159-188.

Simon, G. (1995): Géodynamique des migrations internationales dans le monde. París: PUF.

Suárez Navaz, L. (2007): "La perspectiva transnacional en los estudios migratorios. Génesis, derroteros y surcos metodológicos". V Congreso sobre la Inmigración en España, Valencia. 
Tarrius, A. (1996): «Territoires circulatoires et espaces urbains. Différenciation des groupes migrants». En Morokvasic, M. y Rudolph, H. (eds.): Migrants, les nouvelles mobilités en Europe. París: L'Harmattan. 93-117.

- (2001): "Au-delà des États-nations: des sociétés de migrants". Revue Européenne des Migrations Internationales, 17 (2): 37-61.

Todd, E. (2011): L'origine des systèmes familiaux. Tomo 1: l'Eurasie. París: Gallimard.

Turner, V. (1967): La selva de los simbolos. Madrid: Siglo XXI.

Vertovec, S. (2009): Transnationalism. Londres-Nueva York: Routledge.

Viruela Martínez, R. (2006): “Inmigrantes rumanos en España: Aspectos territoriales y procesos de sustitución laboral”. Scripta Nova. Revista Electrónica de Geografía y Ciencias Sociales X (222).

Vygotsky, L. S. (1979): El desarrollo de los procesos psicológicos superiores. Barcelona: Editorial Crítica.

Weber, S. (2009): “Les mobilités induites par les migrations: Émergence d'un champ circulatoire transnacional”. Méditerranée, 113: 121-126.

Wellman, B. (1997): "El análisis estructural: del método y la metáfora a la teoría y la sustancia". Debates en sociología, 22: 47-97.

Wihtol de Wenden, C. (2001): “Un essai de typologie des nouvelles mobilités". Hommes E migrations, 1233: 5-12.

Willis, P. E. (1977): Aprendiendo a trabajar: cómo los chicos de la clase obrera consiguen trabajos de clase obrera. Madrid: Ediciones AKAL. 